\title{
A Survey of the Cause and Effects of Mountain Ridge "Black Wind” in a Five Year Period to Save Mountaineers
}

\section{Sepehri $\mathrm{J}^{1^{*}}$, Zareie $\mathbf{P}^{2}$, Ashkeshi $\mathrm{K}^{3}$ and Anjafi $\mathbf{S}^{3}$}

${ }^{1}$ GTAFA Learning Centre, 10200 Yonge Ave, Richmond Hill, ON L4C 3B6, Canada

${ }^{2}$ Tutor Doctor, Richmond Hill, ON, Canada \& Toronto Farsi School, 5635 Yonge St, North York, ON M2N 5S3, Canada

${ }^{3}$ Mountaineering \& Sport Climbing Federation, Tehran, Iran

*Corresponding author: Sepehri J, GTAFA Learning Centre, 10200 Yonge Ave, Richmond Hill, ON L4C 3B6, Canada, Tel: (416)-821-2987; E-mail: jeff.sepehri@gmail.com

Received date: Apr 19, 2016; Accepted date: May 16, 2016; Published date: May 19, 2016

Copyright: @ 2016 Sepehri J, et al. This is an open-access article distributed under the terms of the Creative Commons Attribution License, which permits unrestricted use, distribution, and reproduction in any medium, provided the original author and source are credited.

\begin{abstract}
This paper is the first of its kind about a specific kind of gusty wind, named "Black Wind", which blows over Iranian mountain ridges which has claimed mountaineering victims who have been trapped in these situations, every year, especially in February to April. Black Wind is experienced by mountain climbers at ridge level when hiking across a crest to a peak. This phenomenon is a serious concern for climbers.
\end{abstract}

Keywords: Black wind, Wind shear, Jet stream

\section{What is Low Level Wind Shear?}

Wind shear, or wind gradient, is a difference in wind speed or direction over a relatively short distance in the atmosphere. Wind shear is a micro scale meteorological phenomenon occurring over a very small distance. Atmospheric wind shear is normally described as either vertical or horizontal wind shear. Vertical wind shear is a change in wind speed or direction at different altitudes. Horizontal wind shear is a change in wind speed between fixed points on the ground at any given altitude. [1]

Although wind shear can occur at any altitude, it is particularly hazardous for mountain climbers when it happens over a short period of time and near a mountain ridge. Several weather phenomena produce low-level wind shear, such as low-level jets and mountain waves. There is not a Low level wind shear alert system near Iran's Tochal peak.

\section{What is Low Level Jet Stream?}

This phenomena is a kind of Jet Stream (a torrent of wind with a very high speed in core), that happens in a micro scale and at low altitudes. This means that it happens in a short time and in a small area just above mountain tops [2].

Many professional mountaineers lose their lives because the LLJ, which pushes and hurls them off the mountain. This air current cannot be seen on meteorological synoptic prediction maps. It happens very quickly and in small locations, so it is unpredictable on maps. As a mountaineer, you should be able to predict it.

\section{The research field}

This phenomenon has been reported many places in Iran mountain zones. We used the one which was the most notorious and nearest to Tehran to survey the phenomenon frequently in specific time intervals. The selected site was around the Mount Tochal peak, which has its highest point at an elevation of $3,933 \mathrm{~m}(12,904 \mathrm{ft})$ and has its coordinates at $35^{\circ} 53^{\prime} \mathrm{N}-51^{\circ} 25^{\prime} \mathrm{E}$.

The most deleterious incidents happen from February to April. We selected the month of April as our instance time and used a five year interval 2007-2012, from 12:00 pm to 03:00 pm, daily.

\section{What is the appearance and detection of Tochal Black Wind?}

The low level wind shear and low level jet stream occur all year around, but in the time interval between of February to April they happen frequently with incredible power which can snatch a strong man or woman easily and toss them a few kilometers away. When this phenomena happens, Kelvin-Helmholtz instability characteristics are seen clearly and lucidly in the sky. Just a few minutes before this event happens, there is a sudden anomalous calm weather [3].

Our local research findings show there is a sensible abatement in air pressure and temperature in micro scale. This is why each mountaineer should trust his/her personal barometer and thermometer for safety.

\section{Graph Analysis}

Graph 1: This line chart demonstrates the average "Black Wind" occurring over Tochal mountain Peak in April over a five year period. In this period, all measurements were taken between 12:00 pm to 03:00 $\mathrm{pm}$. The chart has two vertical axes. The primary one, which is on the left side, indicates the maximum and minimum temperature in centigrade and the secondary vertical axis, which is on the right, represents the LLJ number, distinguished Wind Shear, and "Black Wind" which occurred in this period.

The chart illustrates correlation between the occurrence of LLJ and wind shear with the Black Wind in the first half of the intervals, although it doesn't show the continuity for the whole period. Likewise, the difference between maximum and minimum temperature exposures was less possible with a Black Wind increase (Figure 1). 
Citation: Sepehri J, Zareie P, Ashkeshi K, Anjafi S (2016) A Survey of the Cause and Effects of Mountain Ridge "Black Wind" in a Five Year Period to Save Mountaineers. J Climatol Weather Forecasting 4: 167. doi:10.4172/2332-2594.1000167

Page 2 of 2

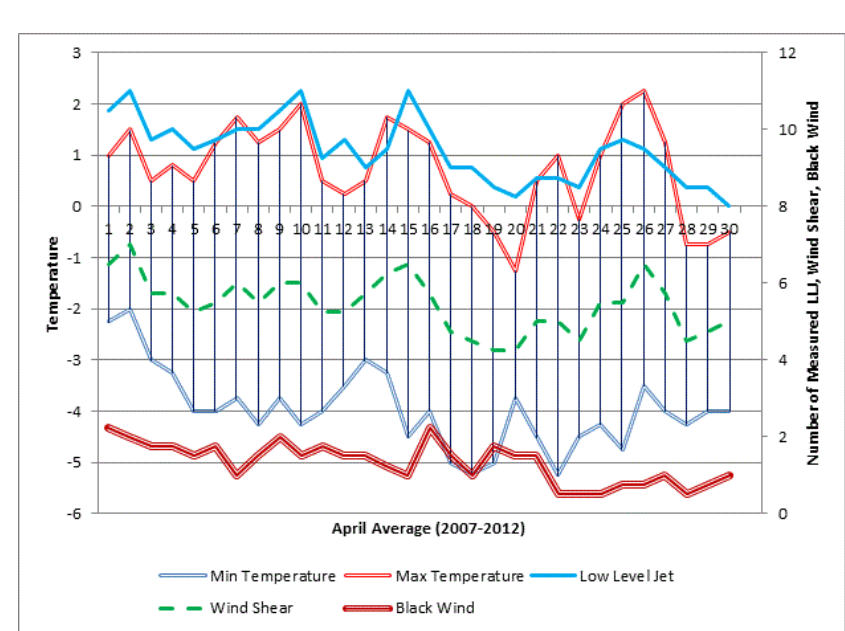

Figure 1: Black Wind Occurs Over Tochal Peack.

To this end there is more Black Wind turn up when there is more of a temperature gradient with more LLJ and simultaneous wind shear simultaneous.

Graph 2: This radar chart with marker illustrates the severity of an occurred Black Wind in the determined interval in our site. The chart demonstrates a spiral and illustrates that the propensity of Black Wind increases counter clock wise (Figure 2).

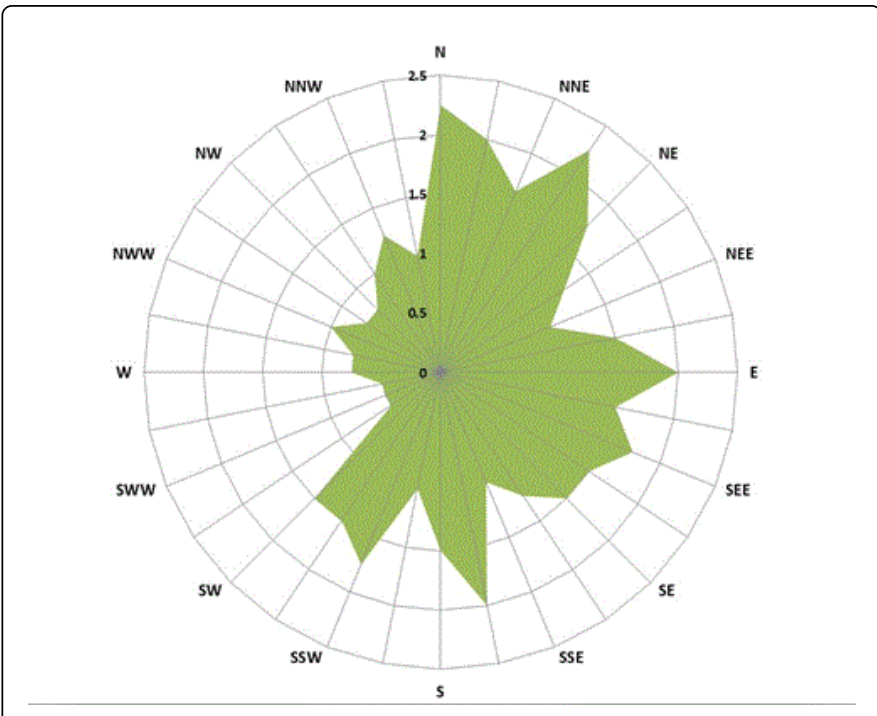

Figure 2: Average recorded black wind around Tochal peak (Aprils: 2007-2012).

\section{Conclusion}

To sum up, Black Wind is a low level wind shear which blows over Central Alborz Mountain Chain, and which, unfortunately, has taken a few mountaineering victims. To protect future lives we should pay attention to sudden decreases in air pressure, temperature and severe change in wind direction and speed. These signs indicate that a Black Wind has started and that the mountaineers have a few seconds to take shelter and/or to pray to be rescued.

\section{References}

1. National Aeronautics and Space Administration (1992), Langley Research Center (June). "Making the Skies Safer From Wind shear".

2. Doyle JD (2008) The influence of meso scale orography on a coastal jet and rain band. Monthly Weather Review 125: 93943-5502.

3. Jafar Sepehri (2013) "Meteorology and Eco Tourism". 